\title{
Elective versus emergency caesarean section: differences in maternal outcome
}

\author{
Anshu Sharma*, Rajiv Acharya, Yashika Pehal, Bhawna Sharma
}

\begin{abstract}
Department of Obstetrics and Gynecology, Shri Guru Ram Rai Institute of Medical and Health Sciences, Dehradun, Uttarakhand, India
\end{abstract}

Received: 25 May 2019

Accepted: 16 July 2019

\author{
*Correspondence: \\ Dr. Anshu Sharma, \\ E-mail: ansh19sagi@yahoo.co.in
}

Copyright: () the author(s), publisher and licensee Medip Academy. This is an open-access article distributed under the terms of the Creative Commons Attribution Non-Commercial License, which permits unrestricted non-commercial use, distribution, and reproduction in any medium, provided the original work is properly cited.

\begin{abstract}
Background: Caesarean section is a life-saving surgical procedure when certain complications arise during pregnancy or labour. The use of CS worldwide has increased worldwide unprecedented levels although the gap between higher- and lower-resource settings remains. The present study evaluates the difference in maternal outcome in elective versus emergency caesarean sections in our institute.

Methods: The study included first 65 cases of emergency caesarean section (group A) and during the study period, first 65 elective caesarean section (group B) if they fulfilled the inclusion criteria. Various intra operative and postoperative events were recorded which included intra operative complications, postpartum haemorrhage and transfusion indices.

Results: The most common indication of caesarean section in group A was fetal distress (27.7\%). In group B most caesarean sections were classified under 5 followed by class 6 , the most common indication being previous caesarean section (27.6\%). It was observed that pre-operative mean haemoglobin in group A was $10.6 \mathrm{~g} / \mathrm{dl}$ and in group B was $11.2 \mathrm{~g} / \mathrm{dl}$. A drop of $1.36 \mathrm{~g} / \mathrm{dl}$ in group A and $1.10 \mathrm{~g} / \mathrm{dl}$ in group B was observed in the post-op period. Cross match / transfusion ratio 1.5 in group $\mathrm{A}$ and 2 in group B, transfusion probability ratio was $60 \%$ in group $\mathrm{A}$ and $66.7 \%$ in group B and transfusion index was 1 in group A and group B. There was significantly higher contraception acceptance in group B compared to group A.

Conclusions: Elective caesarean section has more favourable maternal outcome as compared to emergency caesarean section as the former is done under controlled and planned circumstances. However, there should be stringent audit to scrutinise indication of caesarean section, outcome of caesarean and blood transfusion practices.
\end{abstract}

Keywords: Cross match transfusion ratio, Elective caesarean section, Fetal distress, Maternal morbidity, Previous caesarean section, Transfusion ratio

\section{INTRODUCTION}

Caesarean section is the most common obstetric surgery performed with a view to avert maternal and/or fetal jeopardy.

The soaring rate of caesarean section has been worrisome worldwide with various studies linking increasing caesarean section rates with untoward neonatal outcome and an increase in catastrophic complications like caesarean scar pregnancy and placenta accrete in subsequent gestations.

Compared to vaginal delivery, both maternal mortality and especially morbidity are increased with caesarean birth. The overall maternal mortality rate is $6-22$ deaths 
per 100,000 live births, with approximately one third to one half of maternal deaths after caesarean delivery directly attributes to the surgical procedure and the rest to condition that led to the need of the section. ${ }^{1}$

The outcome of caesarean delivery should not only be limited to a healthy mother and baby at the time of discharge. It must encompass the entire journey of intraoperative and postoperative course which is further influenced by the standard of care, skill of the surgeon and the prevailing circumstances.

Elective caesarean section is done at 39 weeks of gestation ideally although; medical and obstetric conditions determine the gestation at which elective caesarean section is planned. Various studies have shown higher operative complications and longer recovery time in emergency caesarean sections compared to elective caesarean section. ${ }^{2,3}$

In the present study we have compared the indication, haemoglobin drop, and need of blood transfusion and various other aspects of maternal morbidity in planned and emergency caesarean section.

\section{METHODS}

It was a prospective study conducted in Sri Guru Ram Rai Medical and Health Sciences from June 2016 to December 2016. During the study period there were a total of 330 caesarean sections out of 1316 births (caesarean delivery rate $25.07 \%$ ). The total number of elective caesarean section was $112(33.9 \%)$ and emergency caesarean section was $218(66.1 \%)$. The study included first 65 cases of emergency caesarean section (group A) and first 65 elective caesarean section (group B) which fulfilled the inclusion criteria. The patients included in the study were between age group 21-35 years who underwent caesarean section and had a preoperative haemoglobin $\geq 10 \mathrm{~g} / \mathrm{dl}$ and were willing to participate in the study. All patients who had preoperative haemoglobin $\leq 10 \mathrm{~g} / \mathrm{dl}$, antepartum haemorrhage, abnormal placentation, severe pre-eclampsia or eclampsia, other co-morbidities or systemic illness were excluded from the study. Caesarean section was performed by obstetricians who had at least one year of experience after completion of post graduation and had operated on 25 patients independently prior to the study, recorded. Detailed history and examination were done at the time of admission. Indication of caesarean section was classified according to Robson's classification in both the groups. Various intra-operative and postoperative events which included intra-operative complications, postpartum haemorrhage, transfusion indices were recorded. In the postpartum period haemoglobin was estimated after 48 hours of surgery and a fall in haemoglobin was also noted as compared to preop haemoglobin. The difference in the attitude of acceptance of contraception in both groups was also analysed.

\section{RESULTS}

During the study period there were a total of 330 caesarean sections. It was observed that in both the groups majority of the patients were primigravidae (55.4\% group A and $58.5 \%$ group $\mathrm{B}$ )and belonged to age group 21-25 years (46.2\% in group A and $44.6 \% \%$ group B) with mean age of 26.6 years in group A and 27.1 years in group B as seen in Table 1.

Table 1: Demographic profile.

\begin{tabular}{|lllll|}
\hline Parameter & Group A & & Group B & \\
\hline Age (in years) & $\mathbf{N = 6 5}$ & $\mathbf{\%}$ & $\mathbf{N = 6 5}$ & $\mathbf{\%}$ \\
\hline$<20$ & 06 & 9.2 & 05 & 7.6 \\
\hline $21-25$ & 30 & 46.2 & 29 & 44.6 \\
\hline $26-30$ & 23 & 35.3 & 26 & 40 \\
\hline $30-35$ & 04 & 6.1 & 03 & 4.6 \\
\hline$>35$ & 02 & 3.1 & 02 & \\
\hline Mean age & 26.6 & & 27.1 & \\
\hline Booking status & & & 41 & 63.1 \\
\hline Booked & 19 & 29.2 & 24 & \\
\hline Unbooked & 46 & 70.8 & & 41.5 \\
\hline Parity & & & 27 & 58.5 \\
\hline Primigravida & 36 & 55.4 & 38 & 26.2 \\
\hline Multiparous & 29 & 44.6 & & 44.6 \\
\hline Socioeconomic status & & & 17 & 24.6 \\
\hline Class 1 & 14 & 21.5 & 29 & 04.6 \\
\hline Class 2 & 34 & 52.3 & 16 & 03 \\
\hline Class 3 & 15 & 23.1 & & \\
\hline Class 4 & 02 & 03.1 & & \\
\hline
\end{tabular}


Greater number of patients were booked in group B $(63.1 \%)$ compared to group A $(29.2 \%)$ and the difference was statistically significant (p-value <0.001). Most of the patients belonged to modified Kuppuswami's socioeconomic status Class II (52.3\% group A and $44.6 \%$ group B).

The indication of caesarean section in both the groups was categorized according to Robson's criteria and summarised in Table 2. Maximum number of caesarean section in group A come under class 2 of Robson's classification $(23 \%)$ with most common indication of caesarean section in group A being fetal distress $(27.7 \%)$ followed by non-progress of labour (16.9\%). In group B the maximum cases belonged to class 5 followed by class 6 with the most common indication being previous caesarean section (27.6\%) followed by breech presentation in primigravidae $(18.4 \%)$.

The patients with haemoglobin less than $10 \mathrm{~g} / \mathrm{dl}$ were excluded from the study. The haematological parameters and transfusion indices are summarised in Table 3. It was observed that pre-operative mean haemoglobin in group A was $10.6 \mathrm{~g} / \mathrm{dl}$ and in group B was $11.2 \mathrm{~g} / \mathrm{dl}$. Post operative haemoglobin drop was $1.36 \mathrm{~g} / \mathrm{dl}$ in group $\mathrm{A}$ and $1.10 \mathrm{~g} / \mathrm{dl}$ in group B. This difference was not statistically significant. Post-operative parentral iron therapy was given to 21 patients in group $\mathrm{A}$ and 15 patients in group B.

Table 2: Indication of caesarean section (according to robson's criteria).

\begin{tabular}{|c|c|c|c|c|c|}
\hline Category & Indication & Group A & $\%$ & Group B & $\%$ \\
\hline 1 & Nullipara, singleton cephalic $\geq 37$ weeks, spontaneous & 13 & 20 & - & - \\
\hline 2 & Nullipara, singleton cephalic $\geq 37$ weeks, induced & 15 & 23 & 06 & 9.2 \\
\hline 3 & Multipara, singleton cephalic $\geq 37$ weeks, spontaneous & 04 & 6.1 & - & - \\
\hline 4 & $\begin{array}{l}\text { Multipara, singleton cephalic, } \geq 37 \text { weeks, induced, caesarean } \\
\text { section before labour }\end{array}$ & 06 & 9.2 & 09 & 13.8 \\
\hline 5 & $\begin{array}{l}\text { Previous caesarean section, singleton cephalic, } \geq 37 \text { weeks, } \\
\text { spontaneous labour, induced labour, caesarean section before } \\
\text { labour }\end{array}$ & 09 & 13.8 & 18 & 27.6 \\
\hline 6 & $\begin{array}{l}\text { All nulliparous breeches, spontaneous labour, induced labour, } \\
\text { caesarean section before labour }\end{array}$ & 05 & 7.6 & 12 & 18.4 \\
\hline 7 & $\begin{array}{l}\text { All multiparous breeches (including previous caesarean } \\
\text { section), spontaneous labour, induced labour, caesarean section } \\
\text { before labour }\end{array}$ & 03 & 4.6 & 06 & 9.2 \\
\hline 8 & $\begin{array}{l}\text { All multiple pregnancies (including previous caesarean } \\
\text { section), spontaneous labour, induced labour, caesarean section } \\
\text { before labour }\end{array}$ & 03 & 4.6 & 08 & 12.3 \\
\hline 9 & $\begin{array}{l}\text { All abnormal lies (including previous caesarean section but } \\
\text { excluding breech), spontaneous labour, induced labour, } \\
\text { caesarean section before labour }\end{array}$ & 03 & 4.6 & 02 & 3.1 \\
\hline 10 & $\begin{array}{l}\text { All singleton cephalic, } \leq 36 \text { weeks (including previous } \\
\text { caesarean section), spontaneous labour, induced labour, } \\
\text { caesarean section before labour }\end{array}$ & 04 & 6.1 & 04 & 6.1 \\
\hline
\end{tabular}

Table 3: Comparison of haematological parameters and blood transfusion practices between two groups.

\begin{tabular}{|lll|}
\hline Parameter & Group A & Group B \\
\hline Pre op mean $\mathrm{Hb}(\mathrm{gm} / \mathrm{dl})$ & 10.6 & 11.2 \\
\hline Post op mean $\mathrm{Hb}(\mathrm{gm} / \mathrm{dl})$ & 09.5 & 10.1 \\
\hline Fall in $\mathrm{Hb}(\mathrm{gm} / \mathrm{dl})$ & 1.36 & 1.1 \\
\hline Post op parentral iron therapy(n) & 21 & 15 \\
\hline No. of patient cross matched for transfusion & 10 & 03 \\
\hline No. of units transfused & 15 & 06 \\
\hline Patients which needed blood transfusion & 06 & 02 \\
\hline No. of units transfused & 10 & 03 \\
\hline Cross match / transfusion ratio (c/t ratio) & 2.3 & 4.3 \\
\hline Tranfusion probability (no. of patients transfused/ no. of patients cross matched) & 42.8 & 37.5 \\
\hline Transfusion index (no. of patient cross matched for transfusion/ no. of units transfused) & 1 & 1 \\
\hline
\end{tabular}


There were a total of 8 patients who received blood transfusion during intra-operative or postoperative period (Table 3). Out of 8 patients, 6 belonged to group A and 2 belonged to group B ( $p>0.05)$. A total of 15units $(10$ patients) of blood were cross matched in group A and 6 units ( 3 patients) in group B prior to the surgery. The difference in the number of patients subjected to blood cross match prior to caesarean was significant $(\mathrm{p}<0.05$ with $\chi 2$ - test value of 4.2). A total of 10 units were transfused in group A and 3 units were transfused in group $\mathrm{B}$, making a cross match to transfusion ratio1.5 in group $\mathrm{A}$ and 2 in group $\mathrm{B}$. Transfusion probability ratio (number of patients transfused blood / number of patient cross matched $x$ 100) was $60 \%$ in group $A$ and $66.7 \%$ in group B. Transfusion index (Ti) (number of units transfused to number of patient cross matched) was 1 in group A and group B.

Table 4: Postpartum complications in Group A versus Group B.

\begin{tabular}{|c|c|c|c|c|c|c|}
\hline \multirow{2}{*}{ Complications } & \multicolumn{2}{|c|}{ Group A } & \multicolumn{2}{|c|}{ Group B } & \multirow[t]{2}{*}{$\mathrm{X}^{2}$ - test value at $1 \mathrm{DF}$} & \multirow[t]{2}{*}{ p-Value } \\
\hline & $\mathbf{N}$ & $\%$ & $\mathbf{N}$ & $\%$ & & \\
\hline PPH & 11 & 16.9 & 04 & 6.2 & 3.67 & $>0.05$ \\
\hline Bladder injury & - & - & - & - & & \\
\hline Puerpural pyrexia & 07 & 10.7 & 02 & 3.1 & 2.98 & $>0.05$ \\
\hline Wound gaping & 05 & 7.6 & 01 & 1.5 & 2.79 & $>0.05$ \\
\hline
\end{tabular}

As seen in Table 4, postpartum haemorrhage was seen in $11(16.9 \%)$ patients in group A and $4(6.1 \%)$ patients in group B. Wound gaping was seen in $5(7.6 \%)$ patients in group $\mathrm{A}$ and $1(1.5 \%)$ patient in group B. Puerperal pyrexia was observed in $7(10.7 \%)$ cases in group A and $2(3.1 \%)$ cases in group B. The difference was not statistically significant for either of these parameters.

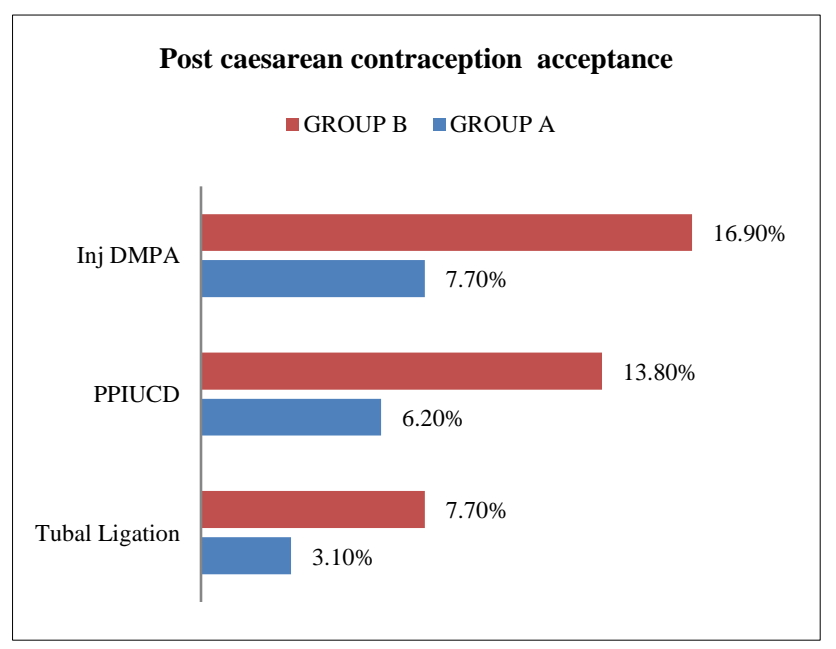

Figure 1: Immediate postpartum contraception acceptance in both the groups.

As shown in Figure 1, a difference in the acceptance of immediate postpartum contraception was observed between group A (11 patients) and group B (25 patients) which was statistically significant $(\chi 2--$ test value of 7.52 and $\mathrm{p}$-value $<0.05)$. Of 11 patients in group $\mathrm{A}$ who agreed for immediate postpartum contraception, 2 accepted postpartum ligation, 4 accepted postpartum IUCD and 5 cases accepted Inj depot medroxyprogesteron acetate whereas in group B of 25 cases, 5 cases accepted postpartum ligation and 9 cases accepted postpartum IUCD and Inj depot medroxyprogesteron acetate was accepted by 11 cases. Average hospitalization due to maternal reason was 5.8 days in group A and 5.1 days in group B.

\section{DISCUSSION}

According to the latest data from 150 countries, currently $18.6 \%$ of all birth score by CS and based onthedatafrom121countries, the trend analysis showed that between 1990 and 2014, the global average CS rate increased $12.4 \%$ (from $6.7 \%$ to $19.1 \%$ ) with an average annual rate of increase of $4.4 \%$. The largest absolute increases occurred in Latin American the Caribbean (19.4\%, from $22.8 \%$ to $42.2 \%$ ), followed by Asia ( $15.1 \%$ from $4.4 \%$ to $19.5 \%){ }^{4}$

During the study period, the incidence of caesarean section in our hospital was found to be $25.07 \%$ and the overall caesarean section delivery rate was $33.9 \%$ for elective caesarean sections and $66.1 \%$ for emergency caesarean sections giving an approximate ratio of $2: 1$ for emergency versus elective caesarean section. The higher incidence of emergency caesarean section depicts the tendency to give opportunity for vaginal delivery as long as feasible and resorting to caesarean section only when the compromise to fetal or maternal health is anticipated.

The most common indication of emergency caesarean was fetal distress and among those electively sectioned was previous one or more caesarean sections. Similarly, in the study conducted by Benzouina $\mathrm{S}$ et al the most frequent indications of elective caesarean section were previous caesarean section delivery and fetal macrosomia and the most frequent indications for emergency caesarean section were fetal distress and previous caesarean section in labour. ${ }^{5}$ Ali et al. have reported in 
their study that in $43.24 \%$ cases, the indication for caesarean section was a previous caesarean delivery and malpresentation was the indication in $11.9 \%$ of cases. ${ }^{6}$ In Najam et al, study, the common indications were the same in elective caesarean group. But in emergency caesarean group, repeat caesarean section was the commonest indication followed by non progress of labour, eclampsia, pre-eclampsia, and cephalopelvic disproportion. ${ }^{7}$ Reducing pregnancy complication by adequate prenatal care may reduce emergency caesarean section. The finding of a significantly greater incidence of emergency caesarean section in mothers with insufficient prenatal care $(29.23 \%)$ as compared with only $9.2 \%$ elective caesarean section, is in consonance with this belief.

Post-operative haemoglobin drop depends upon numerous factors including the indication of section, gestational age, parity, associated medical complication, duration of the surgery, intra-operative events, skill of the surgeon, postpartum haemorrhage and resort to blood transfusion. In our study post operative haemoglobin drop was slightly higher $(1.36 \mathrm{~g} / \mathrm{dl})$ among emergency caesarean section group compared to elective caesarean section group $(1.10 \mathrm{~g} / \mathrm{dl})$ although the difference was not statistically significant. In a study by Singh B et al the average post-caesarean drop in hemoglobin was $1.52 \pm 1.27 \mathrm{gm} / \mathrm{dl}$ and drop in haematocrit was $5.49 \pm 4.1 \%{ }^{8}$ However, there is paucity of literature comparing postoperative drop in haemoglobin in elective and emergency caesarean section.

A Suwal et al reported in their study insignificant difference in the blood loss and blood transfusion among elective and emergency caesarean sections however the incidence of postpartum haemorrhage, fever, UTI, wound infection and hospital stay was significantly higher with emergency caeasarean section. ${ }^{9}$ in our study also, the post partum haemorrhage, blood transfusion, puerperal pyrexia, wound gaping and total hospital stay was higher in emergency caesarean section as compared to elective caesarean section although the difference was statistically significant only for some of these parameters.

There is also a wide variation in blood ordering practices for this commonly performed surgery. Several factors that determine this practice include training, fear of litigation, blood transfusion threshold and cost of cross match. As compared to various studies showing high cross match transfusion ratio $(>2.5) .{ }^{10,11}$ In our study the $\mathrm{C} / \mathrm{T}$ ratio was 1.5 in emergency group and 2 in elective caesarean section, transfusion probability was $60 \%$ and $66.7 \%$ in emergency and elective caesarean group respectively and transfusion index was 1 in both the group. The limited cross match practice in our institute may be attributed to the protocol of checking the availability to group specific blood instead of cross matching as the cross match procedure charges are nonrefundable if transfusion is not administered. In the study done by Singh B et al cross-match to transfusion ratio was 1 , transfusion probability $100 \%$ and transfusion index was 2 which corroborates with the result of our study. ${ }^{8}$

We observed a higher acceptance of postpartum contraception with elective as compared to emergency caesarean section. Repeated counseling about family planning during the antenatal period is of paramount importance for contraceptive acceptance. Since majority of patients who underwent elective caesarean section were obtaining antenatal care, they were primed fora method of postpartum contraception and accepted more easily compared to patients who underwent emergency caesarean section.

\section{CONCLUSION}

After vaginal births elective caesarean section has more favourable maternal outcome as compared to emergency caesarean section as the former is performed in controlled and planned circumstances. There should be stringent audits to scrutinise indication of caesarean section, outcome of caesarean and blood transfusion practices. Further studies on a larger scale are required regarding assessment of factors that influence the other aspects of maternal and neonatal outcome following C.S.

Funding: No funding sources

Conflict of interest: None declared

Ethical approval: The study was approved by the Institutional Ethics Committee

\section{REFERENCES}

1. Khawaja NP, Yousaf T, Tayyeb R. Analysis of caesarean delivery at a tertiary hospital in 17. Phipps MG, Watabe B, Clemons JL, Weitzen Pakistan. J Obstet Gynaecol. 2004;24:139-41.

2. Hannah ME, Hannah WJ, Hewson SA, Hodnett ED, Saigal S, Willan AR. Planned caesarean section versus planned vaginal birth for breech presentation at term: a randomised multicentre trial: Term Breech Trial Collaborative Group. Lancet. 2000;356(9239):1375-83.

3. Bergholt T, Stenderup JK, Vedsted-Jakobsen A, Helm P, Lenstrup C. Intraoperative surgical complication during cesarean section: an observational study of the incidence and risk factors. Acta Obstet Gynecol Scand. 2003;82(3):251-6.

4. Betran AP, Ye J, Moller A-B, Zhang J, Gülmezoglu $\mathrm{AM}$, Torloni MR. The increasing trend in caesarean section rates. Global Regional National Estimates. 1990-2014.PLoSONE11(2):e0148343.

5. Benzouina S, Boubkraoui Mel-M, Mrabet M. Fetal outcome in emergency versus elective cesarean sections at Souissi Maternity Hospital, Rabat, Morocco. Pan Afr Med J. 2016;23:197.

6. Ali M, Hafeez R, Ahmad M. Maternal and fetal outcome; comparison between emergency caesarean 
section versus elective caesarean section. Prof Med J. 2005;12(1):32-9.

7. Najam R, Sharma R. Maternal and fetal outcomes in elective and emergency caesarean sections at a teaching hospital in North India: a retrospective study. JARBS. 2013;5(1):5-9.

8. Singh B, Adhikari N, Ghimire S, Dhital S. Postoperative drop in hemoglobin and need of blood transfusion in cesarean section at Dhulikhel Hospital, Kathmandu University Hospital. Kathmandu Univ Med J (KUMJ). 2013;11(42):144-6.

9. Suwal A, Shrivastava VR, Giri A. Maternal and fetal outcome in elective vs emergency caesarean section. J Nepal Med Assoc. 2013;52(192):563-6.

10. Sripunlom N, Ratchanon S, Ouitrakul S. Appropriateness of routine crossmatch in elective caesarean section for low risk postpartum hemorrhage pregnancies. Clinics Mother Child Health. 2018;15:283.

11. Khan FA, Khan M, Ali A, Chohan U. Estimation of blood loss during Caesarean section: an audit. J Pak Med Assoc. 2006;56(12):572-5.

Cite this article as: Sharma A, Acharya R, Pehal Y, Sharma B. Elective versus emergency caesarean section: differences in maternal outcome. Int $\mathbf{J}$ Reprod Contracept Obstet Gynecol 2019;8:3207-12. 